\title{
Intensive insulin therapy to control hyperglycemia in the critically ill: a look back at the evidence shapes the challenges ahead
}

\author{
James Krinsley' and Jean-Charles Preiser ${ }^{2}$
}

\begin{abstract}
The major interventional trials of intensive insulin therapy in critically ill patients have reached divergent results. The present viewpoint article explores some of the potential reasons, including differences in monitoring technology and protocol design and performance, the occurrence of severe hypoglycemia and changes in the standard of care since publication of the landmark single-center trial. Recently published data detailing the deleterious effect of hypoglycemia are discussed, as is the emerging body of literature describing the important impact of glycemic variability on the risk of mortality in heterogeneous populations of acutely ill and severely ill patients. These new findings have important implications for the design of future interventional trials of intensive insulin therapy in the intensive care unit setting.
\end{abstract}

The story of glucose control has been one of the most passionate discussions in critical care medicine for nearly an entire decade, since publication of the landmark single-center trial of intensive insulin therapy targeting euglycemia in a cohort of mechanically ventilated surgical intensive care unit (ICU) patients [1]. A subsequent trial from the same institution involving medical ICU patients did not yield such strikingly positive results [2], and additional randomized trials have suggested no benefit from this intervention [3-7] or even a modest signal of harm [8]. Nonrandomized trials [9-11] and a large body of observational cohort data from heterogeneous populations [12-14] suggest strongly that a J-shaped or U-shaped mortality curve exists among acutely and

*Correspondence: jkrinsley@stamhealth.org

'Division of Critical Care, Stamford Hospital, 190 West Broad Street, Stamford,

CT 06902, USA

Full list of author information is available at the end of the article critically ill patients, with the lowest mortality occurring among those patients with mean glucose levels during their ICU stay in the range 90 to $120 \mathrm{mg} / \mathrm{dl}$ and higher rates of mortality for those patients with levels below or above this range.

How does one reconcile these seemingly divergent findings? Clearly, based on the rules of evidence-based medicine, recommendations and guidelines $[15,16]$ cannot presently support a widespread implementation of insulin protocols targeting euglycemia; a more conservative and safe effective glucose control approach has been suggested [17] and probably reflects the current practice in many ICUs.

Glycemic control is considerably more complex than most interventions in critical care medicine, helping to explain variances in outcomes of the clinical trials. Very recently, Schultz and collaborators thoroughly reviewed the possible causes of discrepancies between the pioneering trial and the subsequent studies [18]. Monitoring issues include the use of different sources of blood (arterial, venous, capillary) measured using a variety of different monitoring technologies (central laboratory analyzer, portable arterial blood gas analyzer, bedside glucometer) with widely divergent degrees of accuracy [19-21]. Moreover, these measurements are frequently performed in unstable patients with dynamic degrees of insulin resistance and risk of hypoglycemia [22]. Each cycle of measurement and potential modification of therapy is time consuming, and must be repeated every 1 to 4 hours throughout the patient's stay in the ICU [23].

The skill, motivation and experience of the treatment team can influence the protocol performance and a trial's results; these factors may help explain the more positive results emanating from single-center trials. There were 758 and 600 patients in the treatment arm of the two Leuven trials $[1,2]$, and 800 patients in the interventional arm of the before-and-after Stamford trial [9], notable for its positive results and an absence of an increase in severe hypoglycemia $(\mathrm{SH})$, confirmed in several large cohort studies as being independently associated with increased risk of mortality [24-27]. In contrast, there were means of 
only 15 and 26 patients per institution in the interventional arms of the GLUCONTROL trial [3] and the VISEP trial [4]. Skill with protocol performance and the chosen monitoring technology (portable laboratory analyzer vs. bedside glucometer) probably impacted not only the rates of $\mathrm{SH}$, but also the degree to which the interventional cohorts achieved their targeted glycemic range.

Chase and colleagues reported recently in Critical Care that glycemic control using a highly performing algorithm for glycemic control resolved organ failure faster, and for a greater percentage of patients with similar admission and maximum Sequential Organ Failure Assessment scores, than the retrospective conventional control [28]. Moreover, errors in insulin administration are the commonest therapeutic mistakes in ICUs [29]. The change in the standard of care over time that resulted in the control arm of the most recent multicenter trial [8] having a glycemic target range much lower than that used in the first Leuven trial [1] produced a lower degree of glycemic separation between the interventional and conventional cohorts, magnifying the importance of the deleterious effect of hypoglycemia. The commonplace use of insulin for treatment of moderate hyperglycemia has therefore significantly increased the size of a trial that would be adequately powered to potentially demonstrate benefit of the intervention.

An understanding of these factors and a review of emerging themes relating to the dysglycemia of critical illness lays the groundwork for the design and creation of the sorts of interventional trials that will best define the role of glycemic interventional trials in the critically ill patient. While previous trials have focused on control of overall blood glucose (BG) levels, using specific BG targets for the control and interventional arms, recent literature has introduced and reinforced the principle that future trials cannot ignore two other domains of glycemic control: hypoglycemia and glycemic variability (GV).

Although the authors of the Leuven 1 study reported that $\mathrm{SH}$ - defined as BG $<40 \mathrm{mg} / \mathrm{dl}$ - that occurred in $5.1 \%$ of the patients in the interventional arm [1] did not adversely affect outcomes, subsequent analysis of these data, as well as the results of several large observational cohort studies, suggested otherwise [30]. A retrospective analysis of a cohort of 5,365 patients admitted to a single medical-surgical ICU demonstrated that the odds ratio (OR) for mortality associated with a single episode of $\mathrm{SH}$ was 2.28 (95\% confidence interval $(\mathrm{CI})=1.41$ to 3.70 , $P=0.008$ ) [25]. Moreover, a 1:3 nested case:control analysis of 102 patients with $\mathrm{SH}$ from this investigation matched to patients without $\mathrm{SH}$ by age, diagnostic category, diabetic status, treatment era and severity of illness confirmed significantly higher mortality in the patients who experienced $\mathrm{SH}(55.9 \%$ vs. $39.5 \%, P=0.0057)$.
Similarly, Bagshaw and colleagues evaluated the highest and lowest glucose values among 66,184 Australian patients from a mix of 24 ICUs and found that a single episode of $\mathrm{SH}$ was independently associated on multivariable analysis with increased risk of mortality $(\mathrm{OR}=$ 2.6; $95 \% \mathrm{CI}=2.1$ to 3.2) [26]. Egi and coworkers recently published a more in-depth analysis of 4,946 patients from two of these 24 ICUs, and found that even mild degrees of hypoglycemia independently confirmed increased risk of mortality as well as infection. Specifically, the ORs for mortality among groups of patients with varying levels of minimum BG, compared with those patients with nadir BG of 72 to $81 \mathrm{mg} / \mathrm{dl}$, were as follows: 54 to $63 \mathrm{mg} / \mathrm{dl}$, $\mathrm{OR}=1.93(95 \% \mathrm{CI}=1.27$ to $2.95, P=0.002) ; 45$ to $54 \mathrm{mg} / \mathrm{dl}, \mathrm{OR}=2.13$ (95\% CI $=1.29$ to $3.53, P=0.003) ; 36$ to $45 \mathrm{mg} / \mathrm{dl}, \mathrm{OR}=2.14(95 \% \mathrm{CI}=1.20$ to $3.81, P=0.01)$; and $<36 \mathrm{mg} / \mathrm{dl}$, OR $=2.99(95 \% \mathrm{CI}=1.67$ to 5.37 , $P<0.001)$ [27]. Pooled results from the two Leuven studies similarly provide support for the concept that $\mathrm{SH}$ is deleterious in critically ill patients [30]. The OR for mortality among 2,758 medical and surgical ICU patients was 3.23 (95\% CI $=2.25$ to $4.64, P<0.0001)$.

Finally, hypoglycemia is correlated with severity of illness in some studies [25] but not all [30]. While multivariable logistic regression modeling cannot completely exclude the problem of residual confounding, this type of analysis will be the strongest level of evidence available to clinicians; there will never be a randomized, controlled trial of induced hypoglycemia or deliberately increased GV in a cohort of critically ill patients.

There are two clear implications from these studies. First, there can be no doubt that the outcomes of the major interventional trials on intensive insulin therapy in various critically ill populations were significantly affected by the high rates of $\mathrm{SH}$ that occurred among patients in their interventional arms, ranging from $6.8 \%$ of the patients in the NICE-SUGAR trial [8] to $18.7 \%$ in the Leuven medical ICU trial $(25.0 \%$ of those in the ICU for 5 days or more) [2]. Second, future glycemic management interventions must be designed to minimize the occurrence not only of $\mathrm{SH}$, but also of mild to moderate hypoglycemia.

While GV was not on any investigator's radar screen during design, implementation or publication of the interventional trials of glycemic control in the critically ill, new literature has identified $\mathrm{GV}$ as an aspect of glycemic control that may have an even larger bearing on outcomes than does reduction of overall glycemic levels. A retrospective analysis of a cohort of 3,252 patients admitted to a mixed medical-surgical ICU found that those patients in the lowest quartile of GV - based on the standard deviation of the mean glucose level - had an OR for mortality of 0.49 (95\% CI $=0.38$ to $0.63, P<0.0001)$, while those in the highest quartile of GV sustained an 
increased risk of mortality $(\mathrm{OR}=1.81,95 \% \mathrm{CI}=1.47$ to 2.22) [31]. Indeed, among patients with a mean glucose level of 70 to $99 \mathrm{mg} / \mathrm{dl}$ during their ICU stay - at first glance, the patients with the best glycemic control - the mortality ranged from 5.9 to $30.1 \%$ compared with those patients with the lowest and highest variability.

Additional work from this institution demonstrated that the deleterious effect of increased GV was seen only among nondiabetic patients [32], in concordance with a stream of literature suggesting that hyperglycemia in critically ill patients has a much greater adverse effect among nondiabetics than among diabetics [33-35]. Other retrospective investigations among a variety of different patient populations have confirmed that increased GV is independently associated with increased risk of mortality [36-39].

Finally, the Leuven investigators recently published the first analysis of the effect of GV in a prospective randomized controlled trial [30]. This important investigation confirmed that increased GV was independently associated with increased risk of mortality, both in the medical ICU and the surgical ICU studies. Moreover, the intervention - intensive insulin therapy - failed to reduce $\mathrm{GV}$, and in fact tended to increase GV in both cohorts. Failure to improve GV may therefore have diminished the beneficial effects of the intervention, providing support for the inclusion of this domain of glycemic control as a secondary endpoint in future interventional trials [40].

The importance of these observations is strengthened by their biologic plausibility. Indeed, in vitro, a high glucose variability can induce apoptosis of endothelial cells and impairment of the cellular signaling in monocytes $[41,42]$. These effects may be mediated via wide changes in osmolarity that in turn could affect cellular and organ function [43]. Previous investigations in diabetics have suggested that serum markers of endothelial dysfunction and oxidative stress are increased in those patients who experience glucose fluctuation independent of the average glucose exposure [44]. Harm to the microvasculature mirrored by the elevation of markers of endothelial dysfunction could hence be further accelerated by hyperactive inflammatory cells. Finally, although the most speculative, perhaps the most important reason why increased GV may be associated with worsened ICU outcomes is the fact that significant hypoglycemia could occur undetected. Because continuous glucose monitoring has not yet been widely used in ICU patients, no active surveillance program can eliminate the possibility that significant glucose swings are occurring.

Future interventional trials of insulin therapy in critically ill patients must therefore control all three domains of BG control: lowering overall glycemic levels, while minimizing both GV and hypoglycemia. There are several approaches that may, in combination, help ICU teams achieve the best possible outcomes [45]. One such approach is the use of computerized algorithms to improve work flow, increase adherence to glycemic targets and minimize errors in insulin dosing, resulting in decreased rates of hypoglycemia. In fact, a large multicenter French trial - Computerized Glucose Control in Critically Ill Patients (CGAO-Rea, Clinicaltrials.Gov NCT01002482) is currently underway to compare the outcome of patients randomized to computer-guided glucose control versus usual care [46]. Additionally, substantial improvements in glycemic protocol performance and decreases in the time burden of the intervention are likely to accrue from the use of accurate continuous or near-continuous glucose monitoring technologies $[47,48]$.

The increased frequency of monitoring resulting from the use of these new monitors should eliminate the occurrence of $\mathrm{SH}$, and should markedly reduce the occurrence of mild to moderate hypoglycemia since the nursing staff attending the patient will have adequate warning to correct the trajectory of BG values before they reach dangerous levels. Moreover, continuous or near-continuous monitoring technology will provide clinicians with a tool to minimize GV, especially with the integration of insulin and nutrition delivery into the treatment algorithms.

In conclusion, glucose can no longer be considered an innocent bystander in the ICU; both hyperglycemia and hypoglycemia harm our patients. The lessons we have learned from the interventional trials performed over the past 9 years and the compelling evidence from recent investigations regarding the impact of hypoglycemia and GV lay the groundwork for the design and implementation of the next generation of trials. While many unanswered questions remain, there can be consensus that the literature has moved past the paradigm of a procon debate and towards a deeper appreciation of the importance of glycemic control in the critically ill patient and the challenges that clinicians still face.

\section{Abbreviations}

$\mathrm{BG}$, blood glucose; Cl, confidence interval; GV, glycemic variability; ICU, intensive care unit; $\mathrm{OR}$, odds ratio; $\mathrm{SH}$, severe hypoglycemia.

\section{Competing interests}

Consulting fees from Medtronic (JK, JCP) and Optiscan (JK) Honoraria for lectures from Edwards (JK, JCP), Roche (JCP) and Medtronics (JCP).

\section{Author details}

'Division of Critical Care, Stamford Hospital, 190 West Broad Street, Stamford, CT 06902, USA. Department of Intensive Care, Erasme University Hospital, 808 route de Lennik, 1070 Brussels, Belgium.

Published: 8 December 2010

\section{References}

1. Van den Berghe G, Wouters P, Weekers F, Verwaest C, Bruyninck, F, Schetz M, Vlasselaers D, Ferdinande P, Lauwers P, Bouillon R: Intensive insulin therapy 
in the critically ill patients. N Engl J Med 2001, 345:1359-1367.

2. Van den Berghe G, Wilmer A, Hermans G, Meersseman W, Wouters PJ, Milants I, Van Wijngaerden E, Bobbaerts H, Bouillon R: Intensive insulin therapy in the medical ICU. N Engl J Med 2006, 354:449-461.

3. Preiser JC, Devos P, Ruiz-Santana S, Mélot C, Annane D, Groeneveld J, lapichino G, Leverve X, Nitenberg G, Singer P, Wernerman J, Joannidis M, Stetcher A, Chioléro R: A prospective randomised multicentre controlled trial on tight glucose control by intensive insulin therapy in adult intensive care units: the GLUCONTROL study. Intensive Care Med 2009, 35:1738-1748

4. Brunkhorst FM, Engel C, Bloos F, Meier-Hellmann A, Ragaller M, Weiler N, Moerer O, Gruendling M, Oppert M, Grond S, Olthoff D, Jaschinski U, John S, Rossaint R, Welte T, Schaefer M, Kern P, Kuhnt E, Kiehntopf M, Hartog C, Natanson C, Loeffler M, Reinhart K; German Competence Network Sepsis (SepNet): Intensive insulin therapy and pentastarch resuscitation in severe sepsis. N Engl J Med 2008, 358:125-139.

5. Arabi YM, Dabbagh OC, Tamim HM, Al-Shimemeri AA, Memish ZA, Haddad SH, Syed SJ, Giridhar HR, Rishu AH, Al-Daker MO, Kahoul SH, Britts RJ, Sakkijha $\mathrm{MH}$ : Intensive versus conventional insulin therapy: a randomized controlled trial in medical and surgical critically ill patients. Crit Care Med 2008, 36:3190-3197.

6. De La Rosa Gdel C, Donado JH, Restrepo AH, Quintero AM, Gonzalez LG, Saldarriaga NE, Bedoya M, Toro JM, Velasquez JB, Valencia JC, Arango CM, Aleman PH, Vasquez EM, Chayarriaga JC, Yepes A, Pulido W, Cadavid CA: Grupo de Investigacion en Cuidado intensivo, GICI-HPTU: Strict glycemic control in patients hospitalised in a mixed medical and surgical intensive care unit: a randomised clinical trial. Crit Care 2008, 12:R120.

7. COIITSS Study Investigators; Annane D, Cariou A, Maxime V, Azoulay E, D'Honneur G, Timsit JF, Cohen Y, Wolf M, Fartoukh M, Adrie C, Santré C, Bollaert PE, Mathonet A, Amathieu R, Tabah A, Clec'h C, Mayaud J, Lejeune J, Chevret S: Corticosteroid treatment and intensive insulin therapy for septic shock in adults: a randomized controlled trial. JAMA. 2010, 303:341-348.

8. The NICE-SUGAR Study Investigators; Finfer S, Chittock DR, Su SY, Blair D, Foster D, Dhingra V, Bellomo R, Cook D, Dodek P, Henderson WR, Hébert PC, Heritier S, Heyland DK, McArthur C, McDonald E, Mitchell I, Myburgh JA, Norton R, Potter J, Robinson BG, Ronco JJ: Intensive versus conventional glucose control in critically ill patients. N Engl J Med 2009, 360:1283-1297.

9. Krinsley JS: Effect of an intensive glucose management protocol on the mortality of critically ill patients. Mayo Clin Proc 2004, 79:992-1000.

10. Reed C, Stewart R, Sherman M, Myers J, Corneille M, Larson N, Gerhardt S, Beadle R, Gamboa C, Dent D, Cohn SM, Pruitt BA Jr: Intensive insulin protocol improves glucose control and is associated with a reduction in intensive care unit mortality. J Am Coll Surg 2007, 204:1048-1054.

11. Scalea TM, Bochicchio GV, Bochicchio KM, Johnson SB, Manjari J, Pyle A: Tight glycemic control in critically injured trauma patients. Ann Surg 2007, 246:605-610.

12. Kosiborod M, Inzucchi SE, Krumholz HM, Xiao L, Jones PG, Fiske S, Masoudi FA, Marso SP, Spertus JA: Glucometrics in patients hospitalized with acute myocardial infarction: defining the optimal outcomes based measure of risk. Circulation 2008, 117:1018-1027.

13. Krinsley JS: Association between hyperglycemia and increased hospital mortality in a heterogeneous population of critically ill patients. Mayo Clin Proc 2003, 78:1471-1478.

14. Falciglia M, Freyberg R, Almenoff PL, D'Alessio DA, Render ML: Hyperglycemia-related mortality in critically ill patients varies with admission diagnosis. Crit Care Med 2009, 37:3001-3009.

15. Dellinger RP, Levy MM, Carlet JM, Bion J, Parker MM, Jaeschke R, Reinhart K, Angus DC, Brun-Buisson C, Beale R, Calandra T, Dhainaut JF, Gerlach H, Harvey M, Marini JJ, Marshall J, Ranieri M, Ramsay G, Sevransky J, Thompson BT, Townsend S, Vender JS, Zimmerman JL, Vincent JL: Surviving Sepsis Campaign: international guidelines for management of severe sepsis and septic shock: 2008. Intensive Care Med 2008, 1:17-60.

16. Moghissi ES, Korytkowski MT, DiNardo M, Einhorn D, Hellman R, Hirsch IB, Inzucchi SE, Ismail-Beigi F, Kirkman MS, Umpierrez GE; American Association of Clinical Endocrinologists; American Diabetes Association: American Association of Clinical Endocrinologists and American Diabetes Association consensus statement on inpatient glycemic control. Endocr Pract 2009, 15:353-369.

17. Krinsley JS, Preiser JC: Moving beyond tight glycemic control to safe, effective glycemic control. Crit Care 2008, 12:149-151.
18. Schultz MJ, Harmsen RE, Spronk PE: Strict or loose glycemic control in critically ill patients - implementing best available evidence from randomized controlled trials. Crit Care 2010, 14:223.

19. Kanji S, Buffie J, Hutton B, Bunting PS, Singh A, McDonald K, Fergusson D, McIntyre LA, Hebert PC: Reliability of point-of-care testing for glucose measurement in critically ill adults. Crit Care Med 2005, 33:2778-2785.

20. Finkielman JD, Oyen LJ, Afessa B: Agreement between bedside blood and plasma glucose measurement in the ICU setting. Chest 2005, 127:1749-1751.

21. Desachy A, Vuagnat AC, Ghazali AD, Baudin OT, Longuet OH, Calvat SN, Gissot $V$ : Accuracy of bedside glucometers in critically ill patients: influence of clinical characteristics and perfusion index. Mayo Clin Proc 2008, 83:400-405.

22. Preiser JC, Devos P, Chiolero R: Which factors influence glycemic control in the ICU? Curr Opin Nutr Metab Care 2010, 13:205-210.

23. Aragon D: Evaluation of nursing work effort and perceptions about blood glucose testing in tight glycemic control. Am J Crit Care 2006, 15:370-377.

24. Lacherade JC, Jacqueminet S, Preiser JC: An overview of hypoglycemia in the critically ill. J Diab Sci Tech 2009, 3:1242-1249.

25. Krinsley JS, Grover A: Severe hypoglycemia in critically ill patients: risk factors and outcomes. Crit Care Med 2007, 35:2262-2267.

26. Bagshaw SM, Egi M, George C, Bellomo R: Early blood glucose control and mortality in critically ill patients in Australia. Crit Care Med 2009, 37:463-470

27. Egi, M, Bellomo R, Stachowski E, French CJ, Hart GK, Taori G, Hegarty C, Bailey M: Hypoglycemia and outcome in critical illness. Mayo Clinic Proc 2010, 85:217-224

28. Chase JG, Pretty CG, Pfeifer L, Shaw GM, Preiser JC, Le Compte AJ, Lin J, Hewett D, Moorhead KT, Desaive T. Chase JG, Pretty CG, Pfeifer L, Shaw GM, Preiser JC, Le Compte AJ, Lin J, Hewett D, Moorhead KT, Desaive T. Organ failure and tight glycemic control in the SPRINT study. Crit Care 2010, 14:R154.

29. Garrouste-Orgeas M, Timsit JF, Vesin A, Schwebel C, Arnodo P, Lefrant JY, Souweine B, Tabah A, Charpentier J, Gontier O, Fieux F, Mourvillier B, Troché G, Reignier J, Dumay MF, Azoulay E, Reignier B, Carlet J, Soufir L; OUTCOMEREA Study Group: Selected medical errors in the intensive care unit: results of the IATROREF study: parts I and II. Am J Respir Crit Care Med 2010, 181:134-142.

30. Meyfroidt G, Keenan DM, Wang X, Wouters PJ, Veldhuis JD, Van den Berghe G Dynamic characteristics of blood glucose time series during the course of critical illness: effects of intensive insulin therapy and relative association with mortality. Crit Care Med 2010, 38:1021-1029.

31. Krinsley JS: Glycemic variability: a strong independent predictor of mortality in critically ill patients. Crit Care Med 2008, 36:3008-3013.

32. Krinsley JS: Glycemic variability and mortality in critically ill patients: the impact of diabetes. J Diab Sci Tech 2009, 3:1292-1301.

33. Krinsley JS: Glycemic control, diabetic status, and mortality in a heterogeneous population of critically ill patients before and during the era of tight glycemic control. Semin Thorac Cardiovasc Surg 2006, 18:317-325.

34. Egi M, Bellomo R, Stachowski E, French CJ, Hart GK, Hegarty C, Bailey M: Blood glucose concentration and outcome of critical illness: the impact of diabetes. Crit Care Med 2008, 36:2249-2255.

35. Graham BB, Keniston A, Gajic O, Trillo Alvarez CA, Medvedev S, Douglas IS: Diabetes mellitus does not adversely affect outcomes from a critical illness. Crit Care Med 2010, 38:16-24.

36. Egi M, Bellomo R, Stachowski E, French CJ, Hart G: Variability of blood glucose concentration and short term mortality in critically ill patients. Anesthesiology 2006, 105:244-252.

37. Dossett LA, Cao H, Mowery NT, Dortch MJ, Morris JM Jr, May AK: Blood glucose variability is associated with mortality in the surgical intensive care unit. Am Surg 2008, 74:679-685.

38. Ali NA, O'Brien JM, Dungan K, Phillips G, Marsh CB, Lemeshow S, Connors AF, Preiser JC: Glucose variability and mortality in patients with sepsis. Crit Care Med 2008, 36:2316-2321.

39. Hermanides J, Vriesendorp TM, Bosman RJ, Zandstra DF, Hoekstra JB, Devries $\mathrm{JH}:$ Glucose variability is associated with intensive care unit mortality. Crit Care Med 2010, 38:838-842.

40. Krinsley JS: Glycemic variability and the end of Chapter One. Crit Care Med 2010, 38:1206-1208.

41. Risso A, Mercuri F, Quagliaro L, Damante G, Ceriello A: Intermittent high glucose enhances apoptosis in human umbilical vein endothelial cells in 
culture. Am J Physiol Endocrinol Metab 2001, 281:E924-E930.

42. Schiekofer S, Andrassy M, Chen J, Rudofsky G, Schneider J, Wendt T, Stefan N, Humpert P, Fritsche A, Stumvoll M, Schleicher E, Häring HU, Nawroth PP, Bierhaus A: Acute hyperglycemia causes intracellular formation of CML and activation of ras, p42/44 MAPK, and nuclear factor KB in PBMCs. Diabetes 2003, 52:621-633.

43. Otto N, Schindler R, Lun A, Boenisch O, Frei U, Oppert M: Hyperosmotic stress enhances cytokine production and decreases phagocytosis in vitro. Crit Care 2008, 12:R107.

44. Monnier L, Mas E, Ginet C, Michel F, Villon L, Cristol JP, Colette C: Activation of oxidative stress by acute glucose fluctuations compared with sustained chronic hyperglycemia in patients with type 2 diabetes. JAMA 2006 295:1681-1687.

45. Dungan KM, Braithwaite SS, Preiser JC: Stress hyperglycaemia. Lancet 2009, 373:1798-1807.
46. Campion TR Jr, May AK, Waitman LR, Ozdas A, Gadd CS: Effects of blood glucose transcription mismatches on a computer-based intensive insulin therapy protocol. Intensive Care Med 2010, 36:1566-1570.

47. Krinsley J, Zheng P, Hall D, Magarian P: ICU validation of the OptiScanner, a continuous glucose monitoring device [abstract]. Crit Care Med 2006, 34:A67.

48. Joseph Jl, Hipszer B, Mraovic B, Chervoneva I, Joseph M, Grunwald Z: Clinical need for continuous glucose monitoring in the hospital. J Diab Sci Tech 2009, 3:1309-1318.

doi:10.1186/cc9275

Cite this article as: Krinsley J, Preiser J-C: Intensive insulin therapy to control hyperglycemia in the critically ill: a look back at the evidence shapes the challenges ahead. Critical Care 2010, 14:330. 